\title{
Pressures secondary to circumferential digital dressings in clay models
}

\author{
Han Joon Kim, Kun Hwang \\ Department of Plastic Surgery, Inha University School of Medicine, Incheon 22332, South Korea.
}

Correspondence to: Dr. Kun Hwang, Department of Plastic Surgery, Inha University School of Medicine, 27 Inhang-ro, Jung-gu, Incheon 22332, South Korea. E-mail: jokerhg@inha.ac.kr

How to cite this article: Kim HJ, Hwang K. Pressures secondary to circumferential digital dressings in clay models. Plast Aesthet Res 2017;4:41-8.

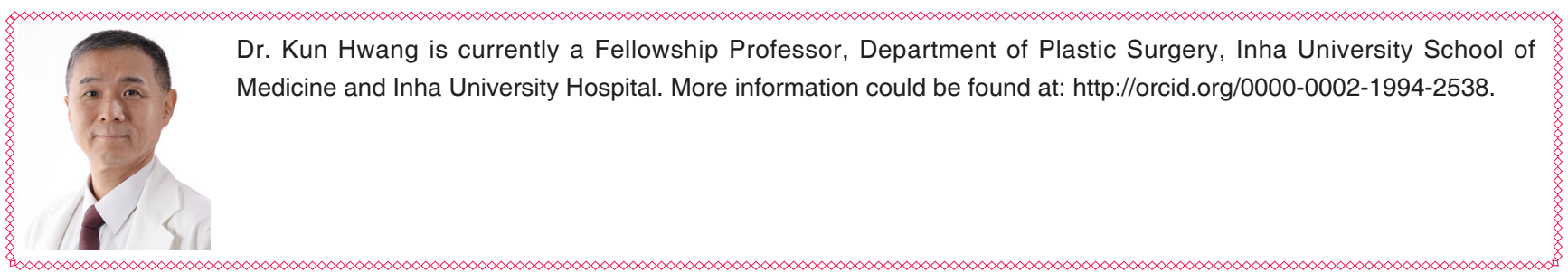

Article history:

Received: 30-10-2016

Accepted: 20-01-2017

Published: 22-03-2017

Key words:

Pressure,

fingers,

compression bandages,

occlusive dressings

\begin{abstract}
Aim: With little manipulation, compression bandages placed circumferentially around the digit can be rolled up the digit, creating a tourniquet effect. The aim of this study was to elucidate the pressures induced by self-adherent bandages applied circumferentially around the fingers. Methods: After fabricating various clay finger models using the live finger as a model, the pressure of each self-adherent bandage was measured at the level of the proximal phalanx. Two different self-adherent bandages were applied with variables of different levels of tightness, number of wraps, and whether each was rolled up or not. Pressure was measured using a digital measuring device at a standardized location. Results: The measured pressure of 3 wraps along the adult finger model was higher than 1 wrap or 2 wraps, and untightened bandages had lower pressures than those of tightened bandages. The pressures of the unrolled bandages were lower than those of rolled up bandages, and pressures along the live finger of the rolled up group were higher than those in the adult finger model. Additionally, measured pressures from the child finger model were higher than those from the adult model. Conclusion: Precautions should be taken to prevent rolling up dressing materials, especially in children.
\end{abstract}

\section{INTRODUCTION}

The hands and fingers are common sites of injury, accounting for an estimated 4.8 million injured persons treated in US hospital emergency departments in 2001 alone. Three million of these injuries involved one or more fingers, of which 1.3 million (44\%) were diagnosed as finger lacerations. ${ }^{[1]}$ To minimize the morbidity associated with these injuries, digital tourniquets are necessary to provide a bloodless environment to

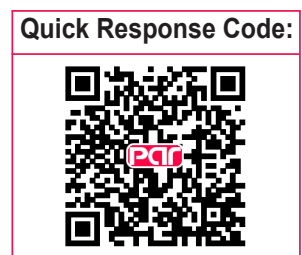


facilitate the identification of deep tissue injuries and foreign bodies. ${ }^{[2]} \mathrm{After}$ the repair of hand lacerations, the wound dressing is usually covered with compression bandages that are applied circumferentially around the digit. Often, dependable tapes are used. However, with very little manipulation, these bandages can be lifted and rolled up the digit distally, creating a tourniquet effect. Vascular insufficiency from an occlusive dressing is an iatrogenic and avoidable complication, and therefore circumferential digital dressings should be applied correctly. ${ }^{[3]}$

To prevent the dressing from rolling up and creating a tourniquet effect, Hart et al. ${ }^{[4]}$ suggested that the dressing should be brought down from the finger, to include the hand and wrist. Despite the importance of preventing finger necrosis, ${ }^{[5,6]}$ the pressures generated by circumferential dressings have not yet been studied. The aim of this study was to elucidate the pressures occurring secondary to self-adherent bandages applied circumferentially around the fingers.

\section{METHODS}

\section{Making a clay finger model}

With clay, finger models of $7 \mathrm{~cm}$ (adult) and $4 \mathrm{~cm}$ (child) in circumference at the level of the proximal phalanx level were made. Biscuit firing was performed. The pressure of each self-adherent bandage was measured using live adult finger models $(7 \mathrm{~cm}$ circumference). A $6 \mathrm{~cm}$ width Peha-haft (Hartmann USA, Inc, Rock hill, SC) and a Coban (3M Co, St. Paul, MN) were used as self-adherent bandages. Experiments were performed with the following variable for each model: dressing materials, wraps, tightness and roll-up states.

\section{Applying methods}

\section{According to the length}

The pressures were measured according to the total length of the elastic dressings:

1C: elastic dressing was wound 1 lap around a finger model with the same length as its circumference $(7 \mathrm{~cm})$. 2C: elastic dressing was wound 2 laps around a finger model with 2 times the length of its circumference $(14 \mathrm{~cm})$. $3 \mathrm{C}$ : eastic dressing was wound 3 laps around a finger model with 3 times the length of its circumference $(21 \mathrm{~cm})$.

\section{According to the tightness}

The pressures were measured according to the tightness of the elastic dressings:

T0: $0 \%$ tightened.

T1: $9.4 \%$ tightened.

T2: $19.7 \%$ tightened.

T3: $33.3 \%$ tightened.

T4: $50.5 \%$ tightened.

\section{Adult finger model}

In the adult finger model, the pressures were measured according to the total length of the bandages without tightening, different tightness using 2 wraps, roll-up states and different dressing materials. According to the total length of the bandages without tightening, the self-adherent bandage was wound 1 (1C-T0), 2 (2C$\mathrm{TO})$, or 3 times (3C-TO) around the finger model with $1(7 \mathrm{~cm}), 2(14 \mathrm{~cm})$, or $3(21 \mathrm{~cm})$ times the length of its circumference. For the different tightness, the selfadherent bandage was wound employing 2 wraps around the finger model with twice $(14 \mathrm{~cm}, 0 \%$ tightened, 2C-T0) the length of its circumference, $91.4 \%(12.8 \mathrm{~cm}$, 9.4\% tightened, 2C-T1), $83.6 \%(11.7 \mathrm{~cm}, 19.7 \%$ tightened, 2C-T2), $75 \%(10.5 \mathrm{~cm}, 33.3 \%$ tightened, 2C-T3), or at $66.4 \%(9.3 \mathrm{~cm}, 50.5 \%$ tightened, $2 \mathrm{C}-\mathrm{T} 4)$ the length of its circumference [Figure 1]. The pressures were measured in both unrolled (NR) and rolled up (R) states. The width of the rolled up portion of the bandage was $6 \mathrm{~cm}$. Pressures were also measured according to the dressing materials, Peha-haft (Ph) or Coban (Co).

\section{Child finger model}

In the child finger model, the same experiments as with adult finger model were done except the different tightness using two wraps. The width of the rolled up portion of the bandage was three $\mathrm{cm}$.

\section{Live adult finger}

In the live adult finger, the same experiments as with child finger model were repeated. The width of the rolled up portion of the bandage was six $\mathrm{cm}$.

\section{Measurements using a pressure sensor}

Pressures were measured using a FlexiForce B201-M pressure sensor, ELFTM system (Tekscan, Inc., South

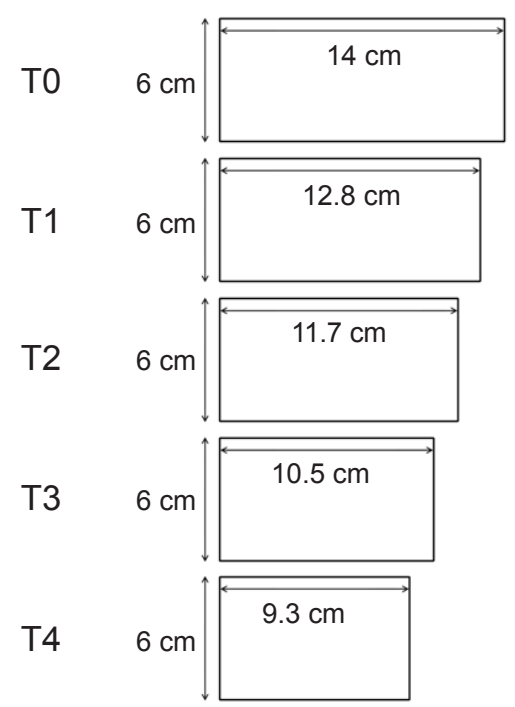

Figure 1: Size of the self-adherent bandages for different tightness 

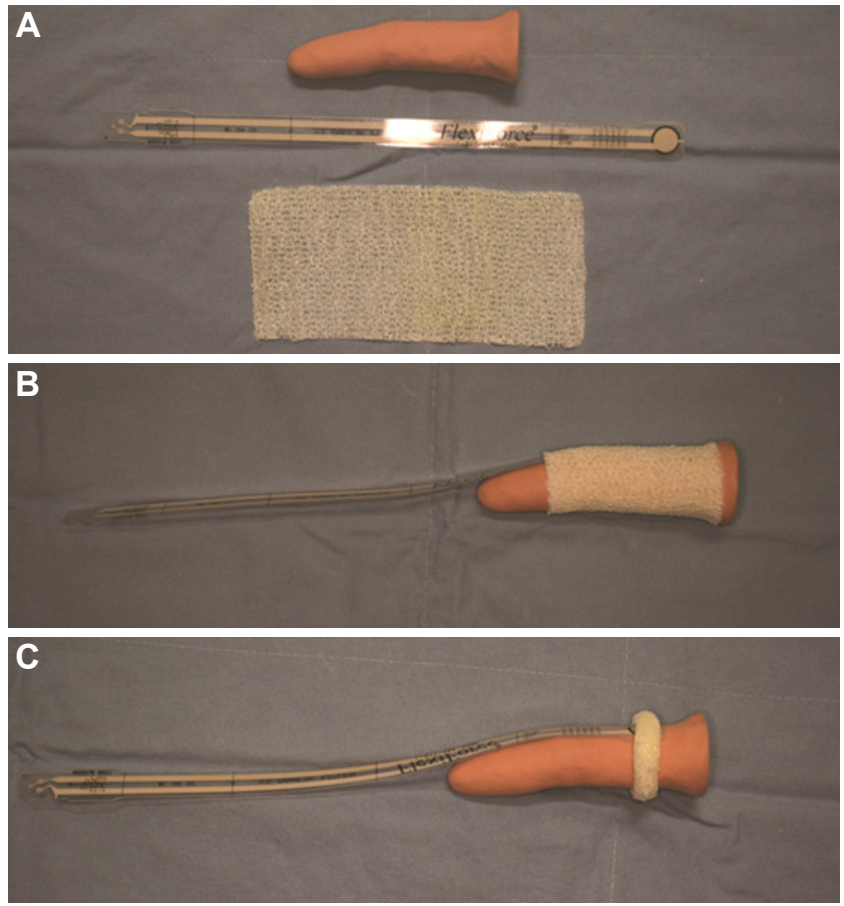

Figure 2: Making a finger tourniquet and pressure measurements. A: finger model, pressure sensor, and self-adherent bandage; B: the sensor was placed in a standardized location and the bandage was wound two wraps around the finger model; C: the bandage was rolled up along the finger model
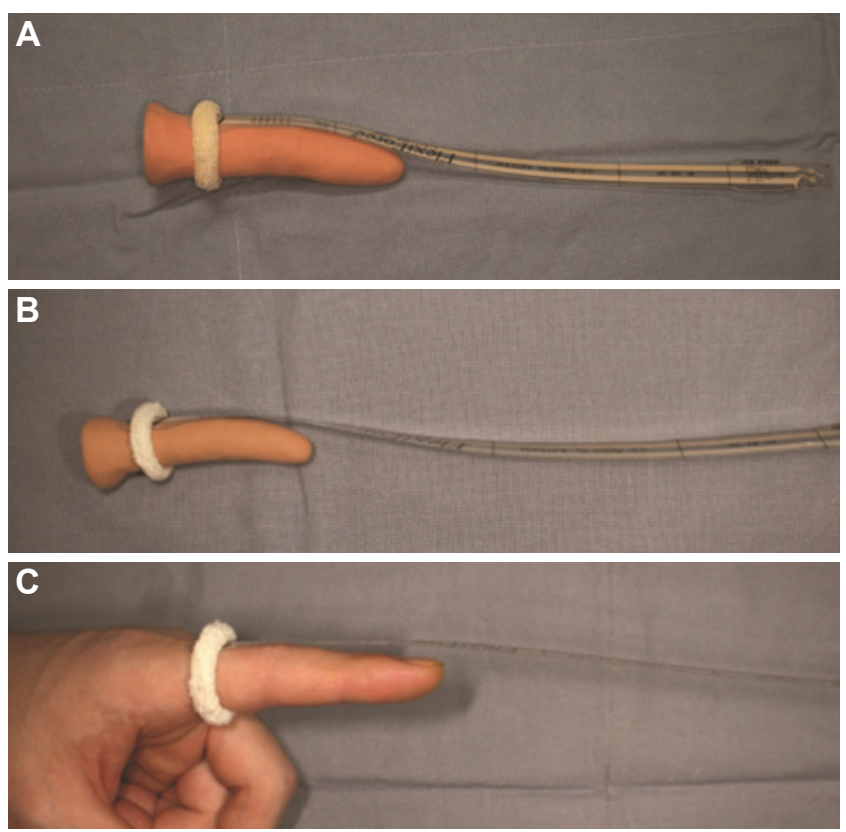

Figure 3: Finger models. A: adult finger model; B: child finger model; C: finger of a living body

Boston, MA), which is a flexible, wafer thin (0.005") $10 \mathrm{~mm}$ diameter disk-shaped sensor designed specifically to measure the force between 2 surfaces without disturbing the dynamics of the test. ${ }^{[2]}$ The sensor was placed in a standardized location on the dorsum of each digit equidistant from the
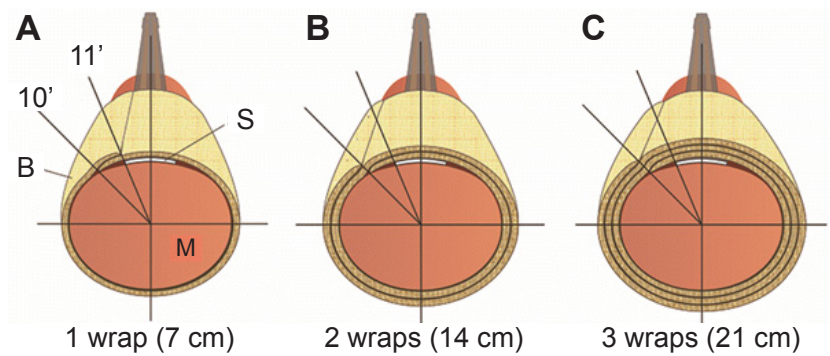

Figure 4: Schematic representation of the location of the pressure sensor (S) and wraps around the finger model (M); B: self-adherent bandage. A: 1 wrap with the same length of its circumference; B: 2 wraps with 2 times the length of its circumference; C: 3 wraps with 3 times the length of its circumference

metacarpophalangeal and proximal phalangeal joints with the reasoning that the pressures of the dorsal and volar surfaces are the same in a circumferential dressing, and pressure measurements of the dorsum are easier to take in living subjects [Figures 2-4]. The pressure sensor was calibrated to measure pressures in the range of 0 to $4,500 \mathrm{~mm}$ of mercury obtained by the Economical Load and Force software program at a refresh rate of $200 \mathrm{~Hz}$. The pressure measurements were made by the same person to prevent bias.

\section{Statstical analysis}

The program SPSS 19.0 (IBM, Armonk, NY) was used for a statistical analysis. For comparison between 2 groups, the independent 2 samples $t$-test was used. For comparison among more than 3 groups, analysis of variance (ANOVA) was used. When the $P$ value was less than 0.05 , the data were interpreted as statistically significant.

\section{RESULTS}

Measured pressures were higher in tighter bandages, in rolled-up bandages, with the use of $\mathrm{Co}$, in the live models, and in adults.

According to the length along the adult finger model (1C-T0, 2C-T0, 3C-T0): the measured pressure of 3 wraps (3C-T0, $384.9 \pm 660.5 \mathrm{mmHg}$ ) was significantly higher than that for 1 wrap (1C-T0, $35.3 \pm 37.5 \mathrm{mmHg}$, $P<0.001)$, or 2 wraps (2C-T0, $44.1 \pm 47.7 \mathrm{mmHg}, P$ $<0.001)$. However, there was no significant difference between 1 wrap and 2 wraps $(P=0.994)$ [Figure 5].

According to the tightness of 2 wraps along the adult finger model (2C-T0, 2C-T1, 2C-T2, 2C-T3, 2C-T4): the measured pressures of the untightened bandages (2C-T0, $44.1 \pm 47.7 \mathrm{mmHg}$ ) were significantly lower than those of the tightened bandages (2C-T1 4, 680.2 $\pm 1,274.1 \mathrm{mmHg}, P<0.001)$. The measured pressures of the untightened bandages and each tightened 


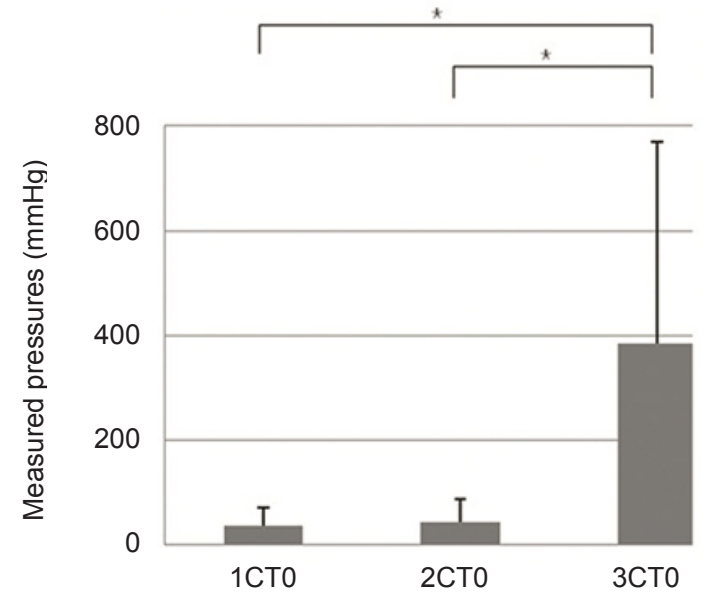

Figure 5: Measured pressures according to the length of the bandage without tightness along the adult finger model. 1CT0: 1 wrap with the same length of its circumference; 2CT0: 2 wraps with 2 times the length of its circumference; 3CT0: 3 wraps with 3 times the length of its circumference. ${ }^{*} P<0.05$

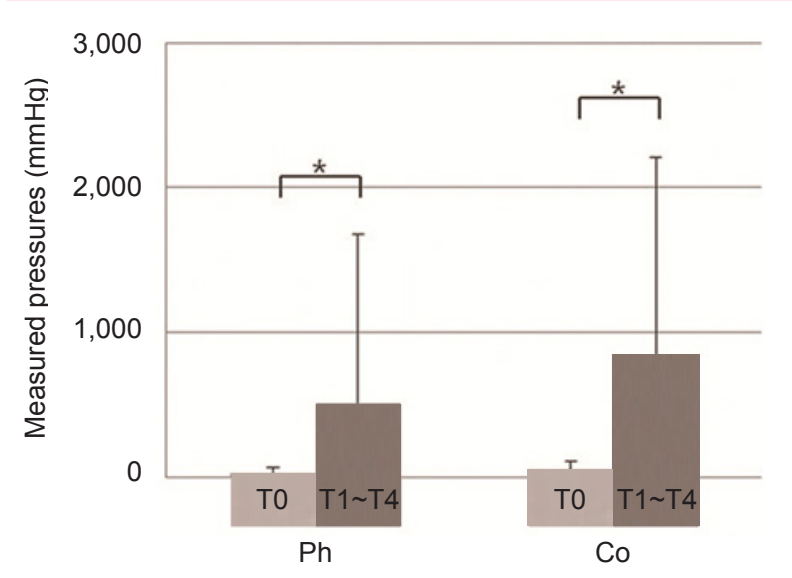

Figure 6: Measured pressures according to the tightness in different materials along the adult finger model. T0: untightened bandage; T1 T4: tightened bandages; Ph: Peha-haft; Co: Coban. ${ }^{*} P<0.05$

bandage were $44.1 \pm 47.7 \mathrm{mmHg}(2 \mathrm{C}-\mathrm{T} 0,0 \%), 61.2 \pm$ $67.4 \mathrm{mmHg}(2 \mathrm{C}-\mathrm{T} 1,9.4 \%), 261.1 \pm 409.5 \mathrm{mmHg}(2 \mathrm{C}-$ $\mathrm{T} 2,19.7 \%), 471.2 \pm 671.3 \mathrm{mmHg}(2 \mathrm{C}-\mathrm{T} 3,33.3 \%)$, and $1,945.0 \pm 1,945.0 \mathrm{mmHg}$ (2 CT4, 50.5\%), respectively. The measured pressures of the 2C-T4 (50\% tightened) were significantly higher $(P<0.001)$ than those in other groups. However, there was no significant difference between the 2C-T0, 2C-T1, 2C-T2, and 2C-T3 parameters $(P>0.05)$. For each material $(\mathrm{Ph}$ and $\mathrm{Co}$ ), the measured pressures of the untightened bandage (T0-Ph, $34.8 \pm 36.6 \mathrm{mmHg}$ ), (T0-Co, $53.5 \pm$ $56.1 \mathrm{mmHg}$ ) was significantly lower than that of the tightened bandage (T1 T4-Ph, $511.9 \pm 1,166.1 \mathrm{mmHg}$, $P<0.001)$, (T1 T4-Co, $848.4 \pm 1,360.2 \mathrm{mmHg}, P<$ 0.001) [Figure 6].

Regarding rolled bandages in the adult finger model $(N R, R)$ : the measured pressures of the unrolled bandages (NR, $14.2 \pm 25.4 \mathrm{mmHg}$ ) were significantly

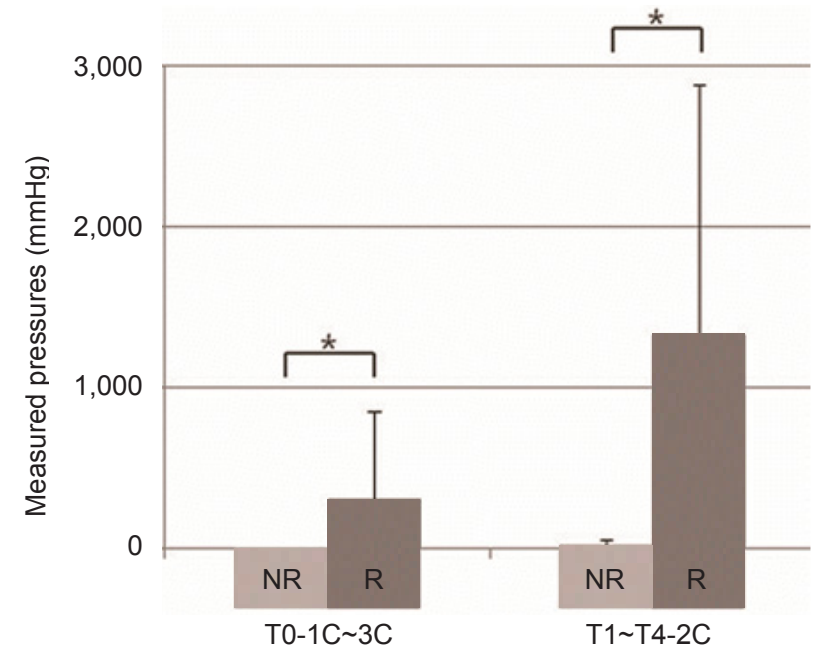

Figure 7: Measured pressures according to the rolling up of untightened dressings and tightened dressings along the adult finger model. NR: unrolled; R: rolled up; T0-1C 3C: untightened bandages; T1 T4-2C: tightened bandages. ${ }^{*} P<0.05$

lower than those of the rolled bandages $(R, 793.1 \pm$ $1,265.7 \mathrm{mmHg}, P<0.001)$. In each untightened and tightened bandage (T0-1C 3C), (T1 T4-2C), the measured pressures of the unrolled bandages (TO1C 3C-NR, $0 \pm 0 \mathrm{mmHg}$ ), (T1 T4-2C-NR, $28.3 \pm 29.9 \mathrm{mmHg}$ ), were significantly lower than those for the rolled bandages (T0-1C 3C-R, $309.6 \pm 544.0 \mathrm{mmHg}, P<$ 0.001), (T1 T4-2C-R, 1,332.0 $\pm 1,551.1 \mathrm{mmHg}, P<$ $0.001)$ [Figure 7].

Regarding rolls of bandages at various lengths along the adult finger model (NR, $\mathrm{R}$ in $1 \mathrm{C}-\mathrm{TO}, 2 \mathrm{C}-\mathrm{TO}, 3 \mathrm{C}-\mathrm{TO})$ : in each wrap (1C-T0, 2C-T0, 3C-T0), the measured pressures of the unrolled bandages (1C-T0-NR, 0 $\pm 0 \mathrm{mmHg}$ ), (2C-TO-NR, $0 \pm 0 \mathrm{mmHg}$ ), (3C-T0-NR, $0 \pm 0 \mathrm{mmHg}$ ) were significantly lower than those of the rolled bandages $(1 \mathrm{C}-\mathrm{T} 0-\mathrm{R}, 70.7 \pm 15.9 \mathrm{mmHg}, P$ $<0.001),(2 \mathrm{C}-\mathrm{TO}-\mathrm{R}, 88.2 \pm 24.0 \mathrm{mmHg}, P<0.001)$, (3C-T0-R, $769.8 \pm 764.0 \mathrm{mmHg}, P<0.001$ ). In the above situations, the same results were yielded for each material (Ph, Co) [Table 1].

Regarding various levels of tightness along the adult finger model (NR, R in 2C-T0, 2C-T1, 2C-T2, 2C-T3, 2C-T4): at each tightness level, bandages of the $2 \mathrm{C}$ group (2C-T0, 2C-T1, 2C-T2, 2C-T3, 2C-T4), measured pressures of the not-rolled up bandage (2C-TO-NR, $0 \pm 0 \mathrm{mmHg}),(2 \mathrm{C}-\mathrm{T} 1-\mathrm{NR}, 0 \pm 0 \mathrm{mmHg}),(2 \mathrm{C}-\mathrm{T} 2-\mathrm{NR}$, $24.8 \pm 25.4 \mathrm{mmHg}),(2 \mathrm{C}-\mathrm{T} 3-\mathrm{NR}, 24.76 \pm 25.4 \mathrm{mmHg}$ ), (2C-T4-NR, $63.9 \pm 14.7 \mathrm{mmHg}$ ) were significantly lower than those for the rolled up bandage (2C-T0-R, $88.2 \pm$ $24.0 \mathrm{mmHg}, P<0.001)$, (2C-T1-R, $122.4 \pm 37.9 \mathrm{mmHg}$, $P<0.001)$, (2C-T2-R, $497.5 \pm 475.3 \mathrm{mmHg}, P<0.001$ ), (2C-T3-R, $917.7 \pm 710.4 \mathrm{mmHg}, P<0.001)$, (2C-T4-R, $3,790.4 \pm 675.2 \mathrm{mmHg}, P<0.001)$. In the above situations, the same results were shown for each 
Table 1: Measured pressures according to the length of different dressing materials and in a rolled up state in the adult finger model (mean \pm SD)

\begin{tabular}{lccc}
\hline Group & NR & $\mathbf{R}$ & $\boldsymbol{P}$ value \\
\hline 1C-T0-Ph & $0.0 \pm 0.0$ & $57.9 \pm 7.2$ & $<0.001$ \\
2C-T0-Ph & $0.0 \pm 0.0$ & $69.5 \pm 12.1$ & $<0.001$ \\
3C-T0-Ph & $0.0 \pm 0.0$ & $114.1 \pm 34.0$ & $<0.001$ \\
1C-T0-Co & $0.0 \pm 0.0$ & $83.5 \pm 10.6$ & $<0.001$ \\
2C-T0-Co & $0.0 \pm 0.0$ & $107.0 \pm 17.0$ & $<0.001$ \\
3C-T0-Co & $0.0 \pm 0.0$ & $1,425.6 \pm 524.9$ & $<0.001$ \\
\hline
\end{tabular}

NR: unrolled; R: rolled up; 1C: elastic dressing was wound 1 lap around a finger model with the same length of its circumference $(7 \mathrm{~cm}) ; 2 \mathrm{C}$ : elastic dressing was wound 2 laps around a finger model with 2 times the length of its circumference $(14 \mathrm{~cm}) ; 3 \mathrm{C}$ : elastic dressing was wound 3 laps around a finger model with 3 times the length of its circumference $(21 \mathrm{~cm})$; T0: 0\% tightened; Ph: Peha-haft; Co: Coban

material (Ph, Co) [Table 2].

Rolling up of different dressing materials along the adult finger model (NR, $\mathrm{R}$ in $\mathrm{Ph}, \mathrm{Co}$ ): for the $\mathrm{Ph}$, the measured pressures of the unrolled elastic dressing (Ph-NR, $7.1 \pm 17.5 \mathrm{mmHg}$ ) were significantly lower than those for the rolled up elastic dressing $(\mathrm{Ph}-\mathrm{R}$, $612.5 \pm 1,217.8 \mathrm{mmHg}, P<0.001)$. For the Co, the measured pressures of the unrolled elastic dressing (Co-NR, $25.3 \pm 30.8 \mathrm{mmHg}$ ) were significantly lower than those for the rolled up elastic dressing (Co-R, $1,175.2 \pm 1,372.4 \mathrm{mmHg}, P<0.001$ ) [Figure 8].

According to the dressing materials along the adult finger model (Ph, Co): the measured pressures of $\mathrm{Ph}$ (Ph, 309.8 $\pm 910.3 \mathrm{mmHg}$ ) were significantly lower than those for Co (Co, 600.2 $\pm 1,126.2 \mathrm{mmHg}, P=0.018$ ). In the unrolled group (NR), the measured pressures of the $\mathrm{Ph}$ (UR-Ph, $7.1 \pm 17.5 \mathrm{mmHg}$ ) were significantly lower than those for Co (UR-Co, $25.3 \pm 30.8 \mathrm{mmHg}$, $P<0.001)$. In the rolled up group $(\mathrm{R})$, the measured pressures of the $\mathrm{Ph}(\mathrm{R}-\mathrm{Ph}, 612.5 \pm 1,217.8 \mathrm{mmHg})$ were significantly lower than those for Co (R-Co,

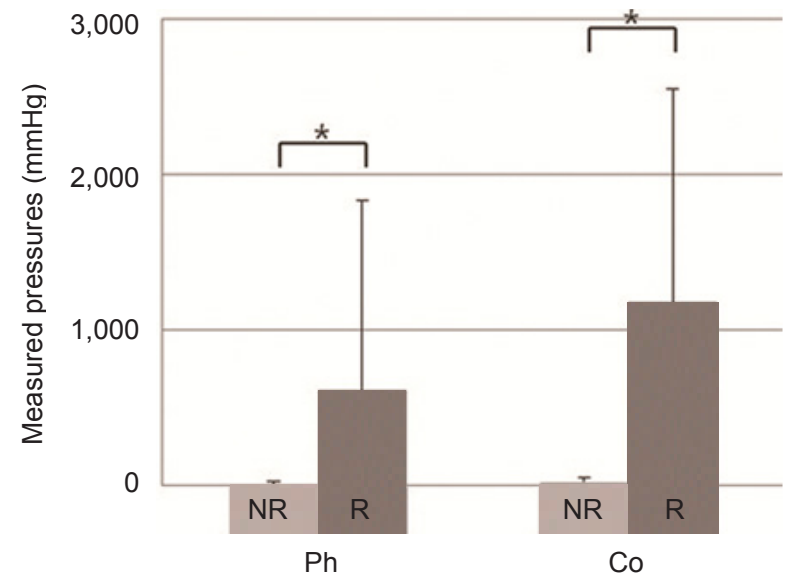

Figure 8: Measured pressures according to the rolling up of the Peha-haft (Ph) and Coban (Co) along the adult finger model. NR: unrolled; R: rolled up. ${ }^{*} P<0.05$
Table 2: Measured pressures according to the tightness of different dressing materials and rolled up state in the adult finger model (mean \pm SD)

\begin{tabular}{lccc}
\hline Group & NR & $\mathbf{R}$ & $\boldsymbol{P}$ value \\
\hline 2C-T0-Ph & $0.0 \pm 0.0$ & $69.5 \pm 12.1$ & $<0.001$ \\
2C-T1-Ph & $0.0 \pm 0.0$ & $87.9 \pm 17.3$ & $<0.001$ \\
2C-T2-Ph & $0.0 \pm 0.0$ & $112.5 \pm 13.7$ & $<0.001$ \\
2C-T3-Ph & $0.0 \pm 0.0$ & $370.6 \pm 156.7$ & $<0.001$ \\
2C-T4-Ph & $49.5 \pm 0.0$ & $3,475 \pm 803.3$ & $<0.001$ \\
2C-T0-Co & $0.0 \pm 0.0$ & $107 \pm 17.0$ & $<0.001$ \\
2C-T1-Co & $0.0 \pm 0.0$ & $156.9 \pm 9.4$ & $<0.001$ \\
2C-T2-Co & $49.5 \pm 0.0$ & $882.5 \pm 383.7$ & $<0.001$ \\
2C-T3-Co & $49.5 \pm 0.0$ & $1,464.8 \pm 613.0$ & $<0.001$ \\
2C-T4-Co & $78.2 \pm 0.0$ & $4,105.8 \pm 309.6$ & $<0.001$ \\
\hline
\end{tabular}

NR: unrolled; R: rolled up; 2C: elastic dressing was wound 2 laps around a finger model with the 2 times the length of its circumference $(14 \mathrm{~cm})$; T0: 0\% tightened; T1: 9.4\% tightened; T2: 19.7\% tightened; T3: 33.3\% tightened; T4: 50.5\% tightened; Ph: Peha-haft; Co: Coban

$1,175.2 \pm 1,372.4 \mathrm{mmHg}, P=0.011$ ) [Figure 9]. In the untightened bandages (T0-1C 3C), the measured pressures of the $\mathrm{Ph}(\mathrm{TO}-1 \mathrm{C} \sim 3 \mathrm{C}-\mathrm{Ph}, 40.2 \pm 46.4 \mathrm{mmHg}$ ) were significantly lower than those for Co (T0-1C 3CCo, $269.3 \pm 562.0 \mathrm{mmHg}, P=0.002$ ). In the tightened dressings (T1 T4-2C), the measured pressures of the $\mathrm{Ph}(\mathrm{T} 1 \sim \mathrm{T} 4-2 \mathrm{C}-\mathrm{Ph}, 511.9 \pm 1,166.1 \mathrm{mmHg})$ and Co (T1 T4-2C-Co, $848.4 \pm 1,360.2 \mathrm{mmHg}$ ) were not significantly different $(P=0.095)$. In 1 and 2 wraps (1CT0, 2C-T0), the measured pressures of the Ph (1C-T0$\mathrm{Ph}, 28.9 \pm 30.1 \mathrm{mmHg}),(2 \mathrm{C}-\mathrm{TO}-\mathrm{Ph}, 34.8 \pm 36.6 \mathrm{mmHg})$ and Co (1C-T0-Co, $41.8 \pm 43.5 \mathrm{mmHg}$ ), (2C-T0-Co, $53.5 \pm 56.1 \mathrm{mmHg})$ were not significantly different $(P$ $=0.285, P=0.220)$. However, for 3 wraps (3C-T0), the measured pressures of the $\mathrm{Ph}(3 \mathrm{C}-\mathrm{TO}-\mathrm{Ph}, 57.0 \pm$ $63.0 \mathrm{mmHg}$ ) were significantly lower than those for Co (3C-T0-Co, $712.8 \pm 815.7 \mathrm{mmHg}, P=0.002$ ). At each different tightness of the bandages of the $2 \mathrm{C}$ group, the measured pressures of the $\mathrm{Ph}$ and $\mathrm{Co}$ were not significantly different except at $19.7 \%$ and $33.5 \%$ of the

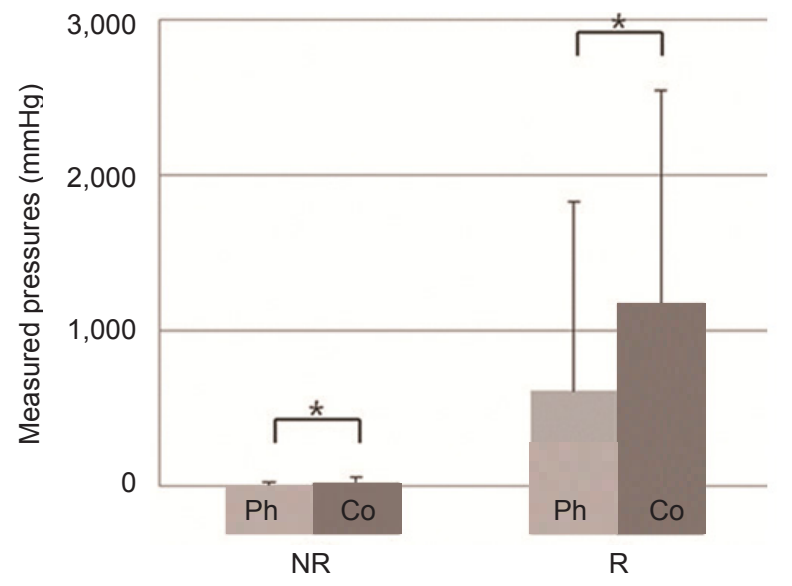

Figure 9: Measured pressures according to the bandage materials in the unrolled group (NR) and the rolled up group (R) along the adult finger model; Ph: Peha-Haft; Co: Coban. ${ }^{*} P<0.05$ 
Table 3: Statistical differences according to rolling up at different lengths in the child finger model (mean \pm SD)

\begin{tabular}{lccc}
\hline Group & NR & R & $\boldsymbol{P}$ value \\
\hline 1C-T0-Ph & $0.0 \pm 0.0$ & $210.6 \pm 117.0$ & $<0.001$ \\
2C-T0-Ph & $0.0 \pm 0.0$ & $323.7 \pm 186.9$ & $<0.001$ \\
3C-T0-Ph & $0.0 \pm 0.0$ & $904.9 \pm 462.1$ & $<0.001$ \\
\hline
\end{tabular}

NR: unrolled; R: rolled up; $1 \mathrm{C}$ : elastic dressing was wound 1 lap around a finger model with the same length of its circumference $(7 \mathrm{~cm}) ; 2 \mathrm{C}$ : elastic dressing was wound 2 laps around a finger model with 2 times the length of its circumference $(14 \mathrm{~cm})$; $3 \mathrm{C}$ : elastic dressing was wound 3 laps around a finger model with 3 times the length of its circumference $(21 \mathrm{~cm})$; T0: $0 \%$ tightened; Ph: Peha-haft

Table 4: Statistical differences according to rolling up at different lengths in the adult finger of a living body $($ mean \pm SD)

\begin{tabular}{lccc}
\hline Group & NR & R & $\boldsymbol{P}$ value \\
\hline 1C-T0-Ph & $0.0 \pm 0.0$ & $277.5 \pm 227.5$ & 0.004 \\
2C-TO-Ph & $0.0 \pm 0.0$ & $636.2 \pm 558.0$ & 0.006 \\
3C-T0-Ph & $0.0 \pm 0.0$ & $1,005.6 \pm 644.5$ & 0.001 \\
\hline
\end{tabular}

NR: unrolled; R: rolled up; 1C: elastic dressing was wound 1 lap around a finger model with the same length as its circumference $(7 \mathrm{~cm}) ; 2 \mathrm{C}$ : elastic dressing was wound 2 laps around a finger model with 2 times the length of its circumference $(14 \mathrm{~cm}) ; 3 \mathrm{C}$ : elastic dressing was wound 3 laps around a finger model with 3 times the length of its circumference $(21 \mathrm{~cm})$; T0: $0 \%$ tightened; Ph: Peha-haft

tightened bandages of the $2 \mathrm{C}$ group. In the $19.7 \%$ and $33.5 \%$ tightened bandages of the $2 \mathrm{C}$ group (2C-T2, $2 \mathrm{C}-\mathrm{T} 3)$, the measured pressures of the $\mathrm{Ph}(2 \mathrm{C}-\mathrm{T} 2-\mathrm{Ph}$, $56.2 \pm 58.5 \mathrm{mmHg}),(2 \mathrm{C}-\mathrm{T} 3-\mathrm{Ph}, 185.3 \pm 218.6 \mathrm{mmHg})$ were significantly lower than those for Co (2C-T2-Co, $466.0 \pm 502.3 \mathrm{mmHg}, P=0.002),(2 \mathrm{C}-\mathrm{T} 3-\mathrm{Co}, 757.2 \pm$ $839.7 \mathrm{mmHg}, P=0.008)$.

Rolling up at different lengths along the child finger model (NR, R in 1C-T0, 2C-T0, 3C-T0): in each wrap using the Ph (1C-T0-Ph, 2C-T0-Ph, 3C-T0-Ph), the measured pressures of the unrolled bandage (1C-T0Ph-NR, $0 \pm 0 \mathrm{mmHg}$ ), (2C-T0-Ph-NR, $0 \pm 0 \mathrm{mmHg}$ ), (3C-TO-Ph-NR, $0 \pm 0 \mathrm{mmHg}$ ) were significantly lower than those for the rolled up bandage (1C-TO-Ph-R, $210.6 \pm 117.0 \mathrm{mmHg}, P<0.001)$, (2C-TO-Ph-R, 323.7 $\pm 186.9 \mathrm{mmHg}, P<0.001$ ), (3C-T0-Ph-R, $904.9 \pm$ $462.1 \mathrm{mmHg}, P<0.001$ ) [Table 3].

Rolling up at different lengths along the live adult finger (NR, R in 1C-T0, 2C-T0, 3C-T0): in each wrap with the $\mathrm{Ph}$ (1C-T0-Ph, 2C-T0-Ph, 3C-T0-Ph), the measured pressures of the unrolled bandage (1C-TO-Ph-NR, 0 $\pm 0 \mathrm{mmHg}$ ), (2C-TO-Ph-NR, $0 \pm 0 \mathrm{mmHg}$ ), (3C-TO-Ph$\mathrm{NR}, 0 \pm 0 \mathrm{mmHg}$ ) were significantly lower than those for rolled up bandage (1C-TO-Ph-R, $277.5 \pm 227.5 \mathrm{mmHg}$, $P=0.004)$, (2C-T0-Ph-R, $636.2 \pm 558.0 \mathrm{mmHg}, P$ $=0.006),(3 \mathrm{C}-\mathrm{T} 0-\mathrm{Ph}-\mathrm{R}, 1,005.6 \pm 644.5 \mathrm{mmHg}, P=$ 0.001 ) [Table 4].

In the rolled up bandage of the untightened group (1C 3C-TO-R), the measured pressures along the adult
Table 5: Statistical differences according to rolling up of adult and child finger models (mean \pm SD)

\begin{tabular}{cccc}
\hline Group & A & B & $\boldsymbol{P}$ value \\
\hline 1C-T0-Ph-R & $57.9 \pm 7.2$ & $210.6 \pm 117.0$ & 0.003 \\
2C-T0-Ph-R & $69.5 \pm 12.1$ & $323.7 \pm 186.9$ & 0.002 \\
3C-T0-Ph-R & $114.1 \pm 34.0$ & $904.9 \pm 462.1$ & 0.000 \\
(1C 3C)-T0-Ph-R & $80.5 \pm 32.1$ & $479.7 \pm 420.8$ & $<0.001$ \\
\hline
\end{tabular}

A: adult finger model; B: child finger model; R: rolled up; $1 \mathrm{C}$ : elastic dressing was wound 1 lap around a finger model with the same length as its circumference $(7 \mathrm{~cm})$; $2 \mathrm{C}$ : elastic dressing was wound 2 laps around a finger model with 2 times the length of its circumference $(14 \mathrm{~cm})$; 3C: elastic dressing was wound 3 laps around a finger model with 3 times the length of its circumference $(21 \mathrm{~cm})$; TO: $0 \%$ tightened; Ph: Peha-haft

Table 6: Statistical differences according to rolling up of the adult finger model and the live finger (mean $\pm S D$ )

\begin{tabular}{cccc}
\hline Group & A & C & $\boldsymbol{P}$ value \\
\hline 1C-T0-Ph-R & $57.9 \pm 7.2$ & $277.5 \pm 227.5$ & 0.014 \\
2C-T0-Ph-R & $69.5 \pm 12.1$ & $636.2 \pm 558.0$ & 0.011 \\
3C-T0-Ph-R & $114.1 \pm 34.0$ & $1,005.6 \pm 644.5$ & 0.002 \\
(1C 3C)-T0-Ph-R & $80.5 \pm 32.1$ & $639.7 \pm 577.1$ & $<0.001$ \\
\hline
\end{tabular}

A: adult finger model; C: finger in living body; R: rolled up; $1 \mathrm{C}$ : elastic dressing was wound 1 lap around a finger model with the same length as its circumference $(7 \mathrm{~cm}) ; 2 \mathrm{C}$ : elastic dressing was wound 2 laps around a finger model with 2 times the length of its circumference $(14 \mathrm{~cm})$; 3C: elastic dressing was wound 3 laps around a finger model with 3 times the length of its circumference $(21 \mathrm{~cm}) ;$ T0: $0 \%$ tightened; Ph: Peha-haft

finger model (1C 3C-T0-R, $80.5 \pm 32.1 \mathrm{mmHg}$ ) were significantly lower than those in the child finger model (1C 3C-T0-R, $479.7 \pm 420.8 \mathrm{mmHg}, P<0.001$ ) and live adult finger (1C 3C-T0-R, $639.7 \pm 577.1 \mathrm{mmHg}, P<$ $0.001)$. In the above situations, the same results were shown for each wrap [Tables 5 and 6].

\section{DISCUSSION}

As material is rolled around a digit, it becomes tighter, exsanguinating the fingertip and constricting the digit. This quickly becomes uncomfortable. If this happens to an adult, the patient will likely cut and remove the constricting device. However, children, especially those two years old and under, do not understand this and cannot remove the dressing quickly. A similar lack of understanding or action also may occur in elderly and mentally compromised patients. If the constriction tightens to the point that all vascular flow is impeded into the tip of the digit, hypoxia and eventually tissue necrosis will occur. Thus, a simple, soft tissue injury can become a more serious injury. Although no studies in the literature have reported the incidence of this condition, any physician who has applied a finger dressing knows how easily a circumferentially applied dressing, such as Co, can roll up when manipulated, as when a child plays with a dressing ${ }^{[4]}$

Lahham et al. ${ }^{[2]}$ noted that digital tourniquet methods 
have complications associated with their use. Necrosis of a digit due to a forgotten tourniquet is an uncommon but catastrophic complication. ${ }^{[7-11]}$ Most complications occur with use of the least conspicuous dressings. ${ }^{[12-16]}$ While digital necrosis secondary to a forgotten tourniquet is the most severe complication related to digital tourniquet use, most complications are related to excessive tourniquet pressure.

Co (3 M Co, St. Paul, MN) is a self-adherent bandage made from a porous, non-woven polyester material, with strands of urethane coated with a cohesive substance. Co sticks only to itself and not to the skin, and provides sustained compression. ${ }^{[17]}$ In soft tissue injuries, it is recommended that $30 \mathrm{~cm}$ of the Co be unwound and allowed to relax because if applied directly from the roll, the tension will be too great. Mendlowitz ${ }^{[18]}$ reported the mean digital arterial systolic blood pressure in adults to be $100 \mathrm{mmHg}$, with a pressure range of 84 to $120 \mathrm{mmHg}$. Based on their experience using digital tourniquets on patients in a clinical setting, Shaw et al. ${ }^{[19]}$ reported pressures of $150 \mathrm{mmHg}$ to be "very adequate" to maintain hemostasis.

Tuncali et al. ${ }^{[20]}$ reported a method for estimation of the arterial occlusion pressure; according to these principles the pressure necessary to prevent digital blood flow ranges from 110 to $140 \mathrm{mmHg}$. In this study, the average pressures in the rolled and untightened bandage group along the live finger were significantly higher than those for the adult finger model. Therefore, dressing materials are not intended to be rolled up on the finger in the clinical setting. Additionally, measured pressures in the child finger model $(479.7 \pm 420.8 \mathrm{mmHg}$, $P<0.001$ ) were significantly higher than those for the adult finger model $(80.5 \pm 32.1 \mathrm{mmHg})$. These results support the need for great caution when using rolled bandages in children. The pressures with the use of Co were relatively higher than those for rolled $\mathrm{Ph}$, which is thought to be due to the thickness of the dressing. The thickness of Co $(2 \mathrm{~mm})$ is thicker than that of $\mathrm{Ph}$ $(1 \mathrm{~mm})$ when unrolled, and therefore it becomes much thicker when rolled. Therefore, great caution is needed to prevent rolling of Co dressings.

In the current study, pressures were measured on a clay model as well as human model. In the human model, limb elevation is an important method used for the prevention of post-dressing limb edema. Limb elevation plays a role in the reduction of finger swelling and improving circulation. The same cannot be done in the clay model. Because all data was obtained based on the clay model instead of live fingers, it cannot be claimed that the data mimics the clinical situation perfectly. This is a limitation of this study.
This study was performed to prevent an over-tightening of bandages in fingers and to make the reader aware of the necessity to anchor the bandage above the wrist. In conclusion, when applying pressure dressings to fingers, great caution is needed to prevent rolling-up which can create a tourniquet effect.

\section{Authors' contributions}

Concept design: K. Hwang

Literature search: K. Hwang

Measurement of the pressure: H.J. Kim

Manuscript's preparation: H.J. Kim, K. Hwang

Manuscript's review: K. Hwang

This paper is made from the a thesis entitled "The Measurement of the Pressures Applied by Selfadherent Bandages to Prevent the Ischemic Damage of the Fingers" by Han Joon Kim, A THESIS Submitted to the faculty of INHA UNIVERSITY in partial fulfillment of the requirements for the degree of MASTER OF SCIENCE, Aug, 2014.

\section{Financial support and sponsorship}

This study was funded by a grant from National Research Foundation of Korea (NRF-2017-005787).

\section{Conflicts of interest}

There are no conflicts of interest.

\section{Patient consent}

Not applicable.

\section{Ethics approval}

All the procedures followed were in accordance with the ethical standards of the responsible committee on human experimentation (institutional or regional) and with the Helsinki Declaration when reporting studies on human beings.

\section{REFERENCES}

1. Conn JM, Annest JL, Ryan GW, Budnitz DS. Non-work-related finger amputations in the United States, 2001-2002. Ann Emerg Med 2005;45:630-5.

2. Lahham S, Tu K, Ni M, Tran V, Lotfipour S, Anderson CL, Fox JC. Comparison of pressures applied by digital tourniquets in the emergency department. West J Emerg Med 2011;12:242-9.

3. Spruiell MD, Messina MJ, Mitchell JJ, Scott FA. A deadly digital dressing: a case of surgical decompression for finger ischemia due to circumferential finger dressing. J Emerg Med 2014;46:655-8.

4. Hart RG, Wolff TW, O’Neill WL Jr. Preventing tourniquet effect when dressing finger wounds in children. Am J Emerg Med 2004;22:594-5.

5. Rozmaryn LM. Closed injuries: bone, ligament, and tendon. In: Rozmaryn LM, editor. Fingertip Injuries. Cham: Springer Int Pub; 2015. p. 11-55.

6. Sullivan W. Finger gangrene case review. Available from: https://www.acep.org/Physician-Resources/Practice-Resources/ Professionalism/Ethics/Finger-Gangrene-Case-Review/. [Last accessed 
on 2011 Jun 24].

7. de Boer HL, Houpt P. Rubber glove tourniquet: perhaps not so simple or safe. Eur J Plast Surg 2007;30:91-2.

8. Avci G, Akan M, Yildirim S, Aköz T. Digital neurovascular compression due to a forgotten tourniquet. Hand Surg 2003;8:133-6.

9. Durrant C, Townley WA, Ramkumar S, Khoo CT. Forgotten digital tourniquet: salvage of an ischaemic finger by application of medicinal leeches. Ann R Coll Surg Engl 2006;88:462-4.

10. Hoare EM. Simple finger tourniquet. Br Med J 1973;3:293.

11. Chen S. Ring tourniquets for fingers. Br Med $J$ 1973;4:174.

12. Hou SM, Liu TK. Salvage of tourniquet-induced thumb necrosis by a modified wrap around procedure. J Trauma 1987;27:803-5.

13. Haas F, Moshammer H, Schwarzl F. Latrogenic necrosis of the big toe caused by left tourniquet: clinical course and reconstruction. Chirurg 1999;70:608-10
14. Karabagli Y, Kose AA, Cetin C. Toe necrosis due to a neglected tourniquet. Plast Reconstr Surg 2005;116:2036-7.

15. Bickel KD. The safety of rolled penrose digital tourniquets for use in local procedures. Plast Reconstr Surg 2004;113:1094.

16. Smellie GD. Exsanguinating digital tourniquet. Br Med J 1973;4:677.

17. Williams C. Coban. Br J Nurs 1995;4:172-4.

18. Mendlowitz M. Measurements of blood flow and blood pressure in clubbed fingers. $J$ Clin Invest 1941;20:113-7.

19. Shaw JA, Demuth WW, Gillespy AW. Guidelines for the use of digital tourniquets based on physiologic pressure measurements. $J$ Bone Joint Surg Am 1985;67:1086-90.

20. Tuncali B, Karci A, Tuncali BE, Mavioglu O, Ozkan M, Bacakoglu AK, Baydur H, Ekin A, Elar Z. A new method for estimating arterial occlusion pressure in optimizing pneumatic tourniquet inflation pressure. Anesth Analg 2006;102:1752-7. 